\title{
Posterior Mediastinal Artery
}

National Cancer Institute

\section{Source}

National Cancer Institute. Posterior Mediastinal Artery. NCI Thesaurus. Code C33367.

The many arteries arising from the thoracic aorta that supply the lymph nodes and pleura of the posterior mediastinum. 